\title{
Emociones, narrativas y prejuicios sexistas. "Las juanitas", un caso de violencia política de género contra mujeres
}

\author{
Emotions, narratives and sexist prejudices. "The Juanitas", a case of political gender violence \\ against women \\ Rosa María González-Victoria ${ }^{a}$
}

\begin{abstract}
:
This article analyzes from an emotional perspective, the media construction of a political case of gender violence against women which detonated in social irritation. Nine newly elected women as federal deputies submitted their resignation leaving their places to their male substitutes. This situation, exposed by the media, led to rage and criticism among different sectors of the population. This study starts showing how emotions, as an analytical dimension play an important role in the ratification of social morality. The methodology is qualitative. Three media discourses are exposed: a chapter of a political analysis television program, a radio news program interview and a written press opinion article. In the emotional framework, the emergence of sexist narratives and prejudices characteristic of a macho culture is detected, as well as a media prosecution of the political parties involved.
\end{abstract}

Keywords:

Media discourses. Gender. Political violence. Emotions.

\section{Resumen:}

En este artículo se analiza una construcción mediática de un caso de violencia política de género contra las mujeres para aproximarse, mediante un enfoque de las emociones, a la irritación social detonada. Se selecciona un acontecimiento relativo a nueve diputadas federales que, recién electas, presentaron su renuncia dejando sus lugares a sus suplentes varones. Para este análisis se parte de las emociones como una dimensión analítica cuya importancia radica en que juegan un importante papel en el refrendo de la moral social. La metodología es cualitativa. Se exponen los resultados preliminares del análisis de tres discursos mediáticos: el capítulo de un programa televisivo de análisis político, una entrevista en un programa informativo de radio y un artículo de opinión de prensa escrita. En el entramado emocional, se detecta la emergencia de narrativas y prejuicios sexistas característicos de una cultura machista, así como un enjuiciamiento mediático a los partidos políticos involucrados.

\section{Palabras Clave:}

Discursos mediáticos, Género, Violencia política, Emociones

Recibido 20 de junio de 2018

Dictaminado: 12 de septiembre de 2018

Segunda versión: 27 de septiembre de 2018

Aceptado: 05 de octubre de 2018

\footnotetext{
a Profesora-investigadora. Doctorado en Ciencias Sociales. Universidad Autónoma del Estado de Hidalgo. Área Académica Ciencias de la Comunicación. Pachuca de Soto, Hidalgo: México, ORCID: https://orcid.org/0000-0001-5740-1823 Email: rgonzalez@uaeh.edu.mx
} 


\section{Introducción}

El proceso ciudadanización y el reconocimiento de los derechos políticos de las mujeres en México ha sido un proceso largo, difícil y áspero (Zavaleta, 2014). Su sistema presidencialista que imperó durante siete décadas, pero sobre todo su sistema sexo/género (Rubin, 1986) enmarcado por una cultura machista, ha obstaculizado y aún sigue obstaculizando su participación, no obstante que este sector representa poco más de la mitad del total de la población del país.

Dicho proceso se inicia durante la primera década del siglo pasado, con la lucha emprendida por grupos de mujeres sufragistas que se sumaron al movimiento antirreleccionista encabezado por Francisco I. Madero (Jaiven \& Rodríguez, 2017) para derrocar la dictadura porfirista. En 1953 se hace realidad, finalmente, la demanda de esos grupos pues las mujeres obtienen el derecho a votar y ser postuladas a puestos de elección popular en todo tipo de elecciones (municipales, estatales y federales).

Es pertinente recordar que unas décadas antes de este logro, mujeres de tres estados del país (Yucatán, San Luis Potosí y Chiapas) ejercían su derecho al voto y participar como candidatas, pero restringido a los niveles estatales y municipales. En 1923, tres mujeres en Yucatán ya habían sido electas para el congreso estatal (Elvia Carrillo Puerto, Raquel Dzib y Beatriz Peniche de Ponce) y una más para regidora del ayuntamiento de Mérida (Rosa Torre). Sin embargo, un año después, con el asesinato del gobernador de esta entidad, Felipe Carrillo Puerto (uno de los principales impulsores de esta iniciativa), las cuatro tienen que dejar los cargos. En 1924, en San Luis Potosí, las mujeres obtuvieron su derecho a participar en las elecciones municipales $\mathrm{y}$, un año después, en las estatales. Y en Chiapas, las mujeres lo lograron en 1925.

Posterior a estos casos, el presidente Miguel Alemán (1946-1952) hace efectiva su promesa de campaña de reconocer el derecho de las mujeres a votar y participar como candidatas; mediante una iniciativa presidencial se reforma el artículo 115 constitucional, la cual se publica en el Diario Oficial de la Federación en 1947. Sin embargo, estos derechos quedan restringidos a los municipios.

Es durante el sexenio de Adolfo Ruiz Cortines (1952-1958) quien, al igual que Alemán Valdés se había comprometido en campaña al reconocimiento de estos derechos, cuando en octubre de 1953 abarca las elecciones federales.
Los principales argumentos que se habían esgrimido hasta entonces para negar los derechos políticos y ciudadanos a las mujeres eran de carácter ideológico y sexista pues consideraban que su labor se encontraba en la esfera privada, al cuidado de la familia y a cargo de las labores domésticas (el trabajo doméstico). En los relatos históricos sobre este proceso se dice que Lázaro Cárdenas del Río, durante su mandato (19341940), envío una iniciativa para que se reformara el artículo 34 constitucional, la cual fue aprobada por las cámaras de Diputados y Senadores y, también, por las legislaturas estatales, pero fue retenida en el cómputo y la declaratoria de su vigencia porque al interior del Partido Nacional Revolucionario (PNR) ${ }^{*}$ se consideró que su voto estaría influido por los curas (Virgen, 2013), como se creía pasaba en España.

Así, después de dichos logros, se emprendieron nuevas acciones -con episodios de resistencia y, aún, de rechazo- para incentivar y apoyar su participación, de tal manera que empezaran a construir su ciudadanía y a ejercer sus derechos políticos; entre las más recientes se registran las siguientes:

- La primera iniciativa de un partido político, el Partido de la Revolución Democrática (PRD) en 1991, para incorporar en sus estatutos un porcentaje mínimo para postular mujeres a puestos de elección popular.

- La reforma el artículo 17, fracción III, del Código Federal de Instituciones y Procedimientos Electorales (Cofipe), en 1993, para que los partidos políticos promovieran una mayor participación de las mujeres en los puestos de elección popular.

- La reforma, en 1996, del artículo 5 de dicho código para determinar que los partidos políticos consideren en sus estatutos que, del total de las candidaturas para ocupar curules en las dos cámaras, el $70 \%$ de las personas postuladas sean del mismo género.

- La introducción, en 2002, de las "cuotas de género" como una acción afirmativa la cual, por cierto, es impugnada por integrantes del Partido

\footnotetext{
* Partido que después cambió su denominación a Partido de la Revolución Mexicana (PRM) y luego a Partido Revolucionario Institucional (PRI).
} 
Acción Nacional (PAN) argumentando que contradecía el precepto constitucional de igualdad entre hombres y mujeres. En respuesta a su impugnación, la Suprema Corte de Justicia de la Nación declara que esta acción no es anticonstitucional. Poco después, en el código queda establecida su cumplimiento como una obligación.

- En 2008, el mandato (también en el Cofipe) de que del total de las candidaturas a las dos cámaras, los partidos o coaliciones queden integradas con al menos el $40 \%$ de aspirantes propietarios de un mismo género, quedando excluidas de esta disposición las candidaturas de mayoría relativa resultado de un proceso de elección democrático.

- La determinación, en 2011, de la Sala Superior del Tribunal Electoral del Poder Judicial de la Federación (TEPJF) de que las fórmulas de las candidaturas queden integradas por personas del mismo género como consecuencia de la renuncia de nueve diputadas federales recién electas (Barquet, 2012). En septiembre del 2009, estas legisladoras dejan sus puestos para que entren sus suplentes, todos ellos varones. Este caso que será denominado "las juanitas", en alusión al que fuera candidato del Partido de Trabajo (PT), se retomará más adelante.

Así, en estos años de lucha, entre resistencias, críticas y rechazo, las mujeres logran elevar su presencia en puestos de elección popular; por ejemplo, en el número total de las presidencias municipales $(2,446)$, en 2005 ocupan el $3.6 \%$; en 2012, 7\%; en 2014, 7.3\%.; en 2015, $9 \%$ y, en 2016, 14\% (Editores, 2017).

Un tema electoral que entre los grupos feministas de activistas y de académicas llamó la atención fue el registrado en el Distrito Federal (hoy Ciudad de México), donde del 2000 al 2015, esto es, durante el periodo de restitución de la totalidad de los derechos ciudadanos y políticos de sus habitantes*, 27 mujeres lograron ocupar el cargo de delegadas y jefas delegacionales (cargo

\footnotetext{
"Su ciudadanía no tenía derecho a elegir, mediante el voto, a sus autoridades locales.
}

equivalente a la de presidencias municipales): cinco en el año 2000 (esto es, el 31.25\% del total de las demarcaciones); ocho en 2003, cantidad que representa la mitad del total de las delegaciones. En la actualidad, se redujo a cuatro, sin embargo, cabe mencionar que antes de este proceso de restitución de los derechos de su ciudadanía, de 1976 al 2000, sólo diez mujeres habían sido designadas para ocupar el cargo de delegadas y ninguna a la de una gubernatura (González \& Araiza, 2018).

Por cierto, de la década de 1970 al 2016, sólo siete mujeres habían sido gobernadoras, en igual cantidad estados de los 31 que componen al país ${ }^{\dagger}$.

En lo concerniente a su participación en las cámaras (de Senaduría y Diputación) que conforman el Congreso de la Unión, el proceso ha sido más significativo. El Instituto Nacional de las Mujeres (Inmujeres, 2015) estima que en la LXIII legislatura del Congreso de la Unión, había un total de $34.4 \%$ senadoras y $42.4 \%$ diputadas. Además de que de 1988 al 2017, sólo cinco mujeres se habían postulado a la presidencia de la República.

En este contexto, la renuncia de nueve diputadas federales $^{\ddagger}$ de la LXI Legislatura, para dejar sus escaños a sus suplentes varones, provoca una ola de críticas en redes sociales y medios de comunicación tradicionales, así como irritación entre varios sectores sociales. En cuanto se difunde la noticia, se incrementan y comienzan a ser nombradas "las juanitas", aludiendo a un caso registrado de manera reciente. Esta denominación hacía referencia al candidato postulado por el PT para contender por la jefatura de la delegación de Iztapalapa, Rafael Ponfilio Acosta Ángeles, conocido como "Juanito".

Acosta Ángeles había aceptado delegar el cargo a Clara Brugada, después de un acuerdo público asumido con quien entonces era considerado el líder moral del PRD, Andrés Manuel López

\footnotetext{
† Cuando se inicia el proceso de restitución los derechos de la población de la capital para elegir a sus autoridades, es nombrada por primera vez una mujer (Rosario Robles Berlanga) para ocupar la jefatura de gobierno (antes denominada Regencia, cuando eran designados por el presidente del país en turno) ya que quien estaba al frente, Cuauhtémoc Cárdenas Solórzano, deja el cargo a quien, en ese momento se desempeñaba en la Secretaría de Gobierno, para postularse, por segunda ocasión, como candidato en las elecciones presidenciales.

* Algunos analistas refieren a ocho, otros a siete, nueve e, incluso, once. Para los objetivos de este trabajo, se hará referencia a nueve que corresponde a la cantidad registrada por la investigadora Mercedes Barquet Montané en su libro titulado De la inutilidad de la cuota de género. La diputada que no quería ser, publicado por el Tribunal Electoral del Poder Judicial de la Federación, en 2012.
} 
Obrador. Se trataba de un acuerdo para resarcir el triunfo de Brugada como candidata del PRD, anulado por el Tribunal Electoral del Poder Judicial de la Federación (TEPJF), favoreciendo la apelación de Silvia Oliva Fragosa, perteneciente a una de las corrientes que se habían configurado dentro del mismo partido: Nueva Izquierda. Con base en ese acuerdo, López Obrador convoca a la población simpatizante de Brugada a votar por el candidato del PT, luego de que éste aceptó que al ganar dejaría el cargo a Brugada. Al obtener el triunfo, "Juanito" incumple el acuerdo y deja el cargo hasta que se siente sumamente presionado por las críticas, de las cuales no salió bien librado inclusive López Obrador, pues sus adversarios encontraron la oportunidad de continuar atacándolo.

A diferencia de Acosta Ángeles quien, como se señaló, se había comprometido de manera pública a renunciar para dejar el cargo a su suplente, Clara Brugada, se sospecha que en el caso de las llamadas "las juanitas" se trató de un acuerdo hecho en lo privado, en "lo oscurito" como popularmente se dice, prestándose a aparentar que se cumplía con la cuota de género establecida por el Cofipe. Cabe mencionar que, de las nueve legisladoras renunciantes, cuatro pertenecían al Partido Verde Ecologista de México (PVEM); tres al Partido Revolucionario Institucional (PRI), una al PRD y otra más al PT.

Este caso tuvo tal resonancia que provocó y desencadenó un cúmulo de narrativas y prejuicios sexistas, inclusive, entre analistas políticos que se distinguen 0 procuran distinguirse por hacer análisis mesurados, sobre todo, fundamentados académicamente.

El objetivo de este trabajo es analizar una construcción mediática de un caso de violencia política de género contra mujeres para aproximarse, mediante un enfoque de las emociones, a la irritación social que provocó dicha renuncia en un contexto histórico, como se expuso, caracterizado por una ardua lucha de grupos o pequeños contingentes de feministas en contra de los obstáculos y las resistencias, para obtener los derechos políticos y de ciudadanía de las mujeres. De esta forma, se seleccionó dicho acontecimiento registrado en 2009 , el cual produjo una ola de críticas en redes sociales y medios de comunicación y entre varios sectores de la población, así como un enjuiciamiento mediático a los partidos políticos.

En este trabajo se concibe "violencia política de género" contra las mujeres como "todas aquellas acciones y omisiones -incluida la tolerancia- que, basadas en elementos de género y dadas en el marco del ejercicio de derechos políticoselectorales, tengan por objeto 0 resultado menoscabar o anular el reconocimiento, goce y/o ejercicio de los derechos políticos o de las prerrogativas inherentes a un cargo público (Talamás \& Lascurain, 2016: 21) y, en este caso, "impedir la participación de las mujeres por ser mujeres" (Krook \& Restrepo, 2016: 459).

En este caso se parte de la idea de que este tipo de violencia se dio en dos sentidos: 1) un uso de mujeres para aparentar cumplir con las cuotas de género; y 2) su posterior renuncia pues fue percibida en críticas y diversos cuestionamientos como una acción motivada no sólo para simular que se cumplía con dichas cuotas, sino por el hecho de que se trataba de mujeres.

\section{Marco teórico-conceptual}

El estudio de las emociones en las ciencias sociales, regidas mucho tiempo por el paradigma positivista y racionalista, ha despertado interés en el campo de las ciencias sociales, en los últimos años. Se ha reconocido que las emociones son una forma de relacionarse con el mundo, ya que implica apreciaciones y creencias del sujeto que las experimenta. Fericgla (2000) advierte que "las emociones son la matriz sobre la que se mueve la vida social".

La palabra "emoción" proviene del latín emotio, emotionis, palabra que se deriva del verbo emovere que significa "remover", "agitar" o "excitar".

Las emociones como construcción social están sustentadas por varios autores y autoras, como Cornelius quien plantea que "las formas en que fenómenos como la emoción, el yo, la sexualidad y el género están envueltos en las prácticas sociales de la cultura, incluyendo su lenguaje, participan y constituyen parcialmente el orden moral de la cultura y sirven para mantener el orden moral (Cornelius, 1996: 151).

Si bien se reconoce que las emociones están constituidas por elementos físicos y evolutivos, se considera que éstas son constitutivas y constituyentes del sujeto. En este trabajo se presenta una aproximación al entramado emocional que se tejió en un caso de violencia política de género contra mujeres.

Se ha observado un aumento de investigaciones en el campo de la comunicación que parten de 
esta dimensión analítica, con la finalidad de comprender el papel que juegan las emociones en la construcción de mensajes y/o en la interacción comunicativa.

La incorporación de las emociones (y la afectividad), como una dimensión analítica en investigaciones de las ciencias sociales, se inicia en Estados Unidos en los años ochenta del siglo pasado y en Latinoamérica, en los años noventa (Ariza, 2016: 8). Esta dimensión ya había sido considerada entre pensadores de la teoría sociológica clásica y no ignorada como sostienen algunos autores (Tuner, 1994; Synnot, 1992; García Selgas, 1994; citados por Gaytán, 2012: 140) debido al supuesto cartesiano sobre la dualidad constitutiva del sujeto que establece la distinción cuerpo-mente.

En relación a la supuesta ausencia del estudio del cuerpo (y las emociones) en la sociología, Gaytán (2012: 142) aclara que -en realidad- su presencia tenía "una connotación negativa (...) como un componente instintivo, inesperado y salvaje, biológicamente determinado, que debe ser sometido a un control racional por medio de la actitud moral".

Se ha detectado que este aspecto de la vida social estaba presentado entre los autores clásicos de la sociología. Por ejemplo, Durkheim consideraba que la moralidad era un hecho social factible de estudiarse, dado que era externo y tenía un efecto coercitivo en el individuo. Ritzer (2012: 197) sostiene que los estudios del sociólogo francés, además, estuvieron impulsados por el interés que tuvo sobre la "salud" moral. Para Durkheim, la moralidad estaba relacionada con la estructura social.

Al plantear su idea sobre las tres bases que legitiman la autoridad, Weber plantea, por su parte, dos que aluden a un estado emocional: la tradicional y la carismática. De acuerdo con Ritzer (2012: 240), la primera, la tradicional, se fundamenta en la creencia de que existe una santidad en las tradiciones; es decir, en algo no sostenido en lo racional, sino en algo que alude a una emoción de carácter religioso o místico. La segunda base que legitima la autoridad, la carismática, se atribuye a la devoción (esto es, un sentimiento emotivo) de los propios seguidores hacia líderes que son concebidos con poderes especiales, excepcionales, ejemplares, heroicos e, incluso, con cierto aire de santidad.

Simmel, por otro lado, tenía presente el papel que juega tanto el cuerpo como las emociones en la constitución y el mantenimiento de la sociedad.
Gaytán (2010: 146) cita un fragmento de la obra de Simmel para mostrar la importancia social que el autor le atribuyó a esta dimensión para comprender lo social: "Cuando sucede en el campo de los continuos contactos físicos y espirituales, las excitaciones mutuas al placer o al dolor, las conversaciones y los silencios, los intereses comunes y antagónicos, es lo que determina que la sociedad sea irrompible".

Marx fue, quizás, más explícito que los anteriores clásicos de la sociología, al registrar en su obra no sólo su afectividad o estado emocional en sus análisis e interpretación del capitalismo sino en mostrar abiertamente su empatía con la clase obrera, frente al sufrimiento que percibió en su sometimiento a dicho sistema. Scribano (2016) expone que el filósofo, de origen prusiano, muestra su sensibilidad al mencionar la crueldad en la estructura de las fábricas, en los métodos productivos capitalistas impuestos a la clase obrera con el uso de la maquinaria.

\section{Metodología}

El diseño metodológico de este estudio se inscribe en los estudios de caso (Gundarmann, 2008). Es un análisis cualitativo en el que se analizan tres materialidades discursivas mediáticas: el capítulo de un programa televisivo de análisis político, una entrevista de un programa informativo de radio y un artículo de prensa escrita, los tres enfocados a la renuncia de las diputadas, para analizar una construcción mediática de un caso de violencia política de género contra las mujeres, con el objetivo de aproximarse a la irritación social y su enjuiciamiento públicos, es decir, en los medios, mediante un enfoque de las emociones. En este análisis se detecta, en el tejido del entramado emocional, la emergencia de narrativas y prejuicios sexistas propios de una peculiar cultura machista detonada, sobre todo, porque los partidos políticos trastocaron valores y normas socio-políticas establecidos legalmente para el juego político y seguir impulsando la participación de las mujeres, mediante la figura político-electoral de las "cuotas de género".

Para el análisis del corpus, compuesto de las trascripciones del bloque del capítulo del programa televisivo denominado Primer Plano (en la que se analizó el caso), la entrevista del programa informativo de radio "Hoy por Hoy" (tanto de quien formuló las preguntas como de quien las responde) y el artículo de prensa publicado en el diario La Jornada, se recurrió a la noción de 
"narrativas", concibiéndolas como "modalidades del pensamiento $\square$ que $\square$ ordenan la experiencia en una realidad dinámica que trata con intenciones, acciones, vicisitudes y consecuencias que marcan su curso" (Sutton, 2011: 52). En tanto que la noción prejuicio se entenderá como aquella "opinión previa y tenaz, por lo general desfavorable, acerca de algo que se conoce mal", de acuerdo con la definición del diccionario de la Real Academia Española.

Se trata de comprender cómo se construye, mediáticamente, un caso de violencia política de género contra mujeres que desencadena un cúmulo de emociones entre quienes participan en medios de comunicación en su papel de analistas, conductores y personas entrevistadas. Para este análisis, se considera que "Un relato construye dos escenarios, uno en la acción y otro en la conciencia. El primero se enfoca en lo que hacen los sujetos en situaciones particulares, el segundo en lo que involucra acerca de lo que se sabe, se piensa, se siente o no se sabe, no se piensa y no se siente" (Sutton, 2011: 52).

Primer Plano es un programa de análisis político, transmitido una vez a la semana (los lunes), en horario nocturno (de las 22:00 a las 23:00 horas), por el Canal Once, del Instituto Politécnico Nacional (IPN), una institución educativa pública que imparte estudios de nivel medio superior, superior y posgrado. En dicho programa de análisis, desde el año de su creación (1991), ha contado con la participación de una diversidad de analistas como la periodista Carmen Aristegi; los académicos Federico Reyes Heroles, Jesús SilvaHerzog Márquez, Carlos Elizondo Mayer-Serra y Agustín Basave; y el filósofo y político Carlos Castillo Peraza. En la actualidad es conducido por: Lorenzo Meyer y Sergio Aguayo, ambos investigadores de El Colegio de México; María Amparo Casar, José Antonio Crespo y Leonardo Curzio, del Centro de Investigación y Docencia Económicas (CIDE), la primera y el segundo en las áreas de investigación y docencia y el tercero sólo como profesor de dicha institución; y Francisco Paoli Bolio, del Instituto de Investigaciones Jurídicas, de la Universidad Nacional Autónoma de México (UNAM). Cabe destacar la mínima participación de mujeres analistas. Como se observa, en la temporada actual sólo participa una (María Amparo Casar).

Cada capítulo suele ser conducido por cuatro del total de los participantes en el programa. El tema de "las juanitas" fue abordado en el capítulo transmitido el lunes 7 de septiembre del 2009, conducido por Sergio Aguayo, Leonardo Curzio, María Amparo Casar y José Antonio Crespo.

"Hoy por Hoy", por otra parte, es un programa informativo de radio de la XEW-AM, una de las estaciones más antiguas de México, cuyas transmisiones se iniciaron en 1930. En la actualidad es conocida como "W Radio" y se encuentra concesionada a la empresa Televisa. El entonces conductor y director de la primera temporada del programa informativo, Carlos Puig, fue quien abordó el tema de "las juanitas" mediante una entrevista que realizó el 24 de diciembre del 2009 a la diputada federal Enoé Uranga. Este conductor es egresado de la Universidad Iberoamericana, de la licenciatura en Comunicación. En 1997, obtuvo la beca Nieman de la Universidad de Harvard. Tiene una amplia trayectoria laboral en los medios. En 1988 se hizo acreedor, con el equipo de "Hoy en la Cultura", del Premio Nacional de Periodismo, en el ramo de periodismo cultural. Fue columnista del The New York Times, en el blog Latitude y para Bloomberg View; reportero y corresponsal en Washington y jefe de información del semanario Proceso, entre otros cargos. Es el titular del programa de entrevistas "En 15" de Milenio Televisión, columnista de Milenio Diario y director editorial de Milenio Digital. Imparte el taller de Periodismo Jurídico en la maestría de Periodismo del CIDE.

Enoé Uranga, por su parte, es una política, afiliada al Partido de la Revolución Democrática (PRD), quien se asume feminista y es activista en defensa de los derechos de la comunidad LGBT (Lesbianas, Gay, Transgénero y Bisexual). Tiene estudios en sociología y especialidades en las áreas de políticas públicas y derechos humanos, realizados en la Universidad Libre de Berlín, así como en política social y género y en prácticas parlamentarias. Fue presidenta de la Comisión de Derechos Humanos de la Asamblea Legislativa del Distrito Federal y diputada federal.

Jorge Camill, autor del artículo periodístico publicado el viernes 18 de septiembre del 2009, en La Jornada, con el título "Las juanitas de San Lázaro", es analista político, egresado de la UNAM y doctor en derecho por la Universidad de Houston. Este diario es caracterizado por mantener una línea editorial crítica, con un amplio espacio para las organizaciones y movimientos sociales progresistas. Por ello, hay la percepción de que su tendencia es de izquierda. 


\section{Discusión}

En primer término, se exponen resultados preliminares del análisis del programa Primer Plano conducido en esta ocasión -como se mencionó- por cuatro: Sergio Aguayo, Leonardo Curzio, María Amparo Casar y José Antonio Crespo, así como de la entrevista realizada por Carlos Puig a Enoé Uranga y del artículo de Jorge Camil. En las citas textuales incluidas en este trabajo, sólo se colocaron las letras iniciales del nombre o los nombres y el apellido, según corresponda.

En el entramado emocional tejido en el transcurso del tiempo dedicado al tema de la renuncia de las diputadas y algunos diputados y las "cuotas de género", en las tres producciones mediáticas se detectó un entramado de emociones tales como: enojo, ira, vergüenza, frustración, tristeza y nostalgia. Así, este análisis se inicia con Primer Plano.

En el bloque del capítulo donde fue analizado se detectó la activación de seis narrativas, una de la cultura católica, otra, del cancionero popular del bolero, y las siguientes de dichos populares y, también, de la producción intelectual. Con base en estas narrativas se construyeron cinco categorías de análisis. La primera categoría evoca la narrativa de la tentación de Eva: "Caer en el pecado". La segunda, a las mujeres que "venden caro su amor", cuya categoría es: "La aventurera". La tercera alude la tesis de Bourdieu sobre la dominación masculina, por lo que la categoría es: "El dominio masculino". La cuarta corresponde al dicho que dicta que "detrás de un gran hombre, hay una gran mujer"; la categoría es: "Detrás de una mujer, hay un suplente". Y, la quinta, referente a la degradación de la ética y la simulación de los partidos de seguir las normas y reglas establecidas legalmente, la categoría es: "EI contubernio".

Del análisis de la entrevista del programa radiofónico "Hoy por Hoy", emergieron un prejuicio sexista y denigrante, las figuras de quien presta su nombre a otra persona para que ésta oculte su identidad y el suplente, así como una práctica que, de tan recurrente, se ha hecho una costumbre. Con base en éstas, igual que la anterior parte del análisis, se construyeron las categorías de análisis. El prejuicio alude a un uso de mujeres, cuyo papel social de la mayoría y el tono usado por el entrevistador, sugiere que es un varón el autor intelectual quien, además, sostiene con ellas relaciones sexuales intra y extra maritales, así la categoría es: "Las amantes". Las figuras correspondientes a quien presta su nombre a otra persona $y$ el suplente favorecido por el incumplimiento de las "cuotas de género" y de los tratados internacionales, la categoría se construyó a la forma en que fue denominado por la entrevistada: "La prestanombre y el truhan". Y la práctica recurrente, atribuida al PVEM (partido que también fue cuestionado por el grupo de analistas de Primer Plano), la categoría fue construida con base en una práctica atribuida a los pueblos o las comunidades indígenas de México y que también es mencionada por la entrevistada: "Usos y costumbres".

En el análisis del artículo publicado en La Jornada, se detectaron cuatro narrativas muy breves, al igual que los casos anteriores (debido al tiempo y el espacio establecido en sus medios) y una figura. La primera narrativa referida al que fuera el partido único en el poder; la segunda, evocando el título de una canción norteña que proviene del imaginario de una supuesta disposición de la mujer para traicionar a cambio de dinero; la siguiente, referente a burla de las mujeres a las "cuotas de género"; $y$, la cuarta, propia del imaginario sobre la forma en que se realizan las elecciones en México. Con base en estas narrativas se construyeron las siguientes categorías de análisis, las cuales se encuentran enunciadas en el mismo artículo, incluso, una corresponde al título del artículo. Éstas son: "La época dorada del PRI; "Por unas cuantas monedas"; "Las juanitas de San Lázaro"; y, "El fraude".

\section{Primer Plano}

\section{Primera: "Caer en el pecado"}

En culturas occidentales católicas, como la nuestra, es conocida la narrativa del pecado de Eva que relata el haber caído en la tentación de probar el fruto prohibido y, con ello, provocar la expulsión del paraíso de la primera pareja de la creación (Adán y Eva). La narrativa "caer en la tentación" es alusivo a ese episodio. Así, el analista del programa, que dio inicio al capítulo de ese día del programa, evocó esta narrativa, con un tono de ironía, con la expresión "caer en el pecado", pero incluyendo a hombres y mujeres y enjuiciándolos, como "cristianos", mediante un discurso teológico, cuyo primer hilo emocional es a la vergüenza:

Muy buenas noches. Bienvenidos a este nuevo programa de Primer Plano, que inicia con una reflexión teológica, los y las diputadas son pésimos 
cristianos, porque cada que hay un escándalo prometen corregirse. Pero bastan unos cuantos días para que vuelvan a caer en el pecado, en este caso de la degradación y el menosprecio a los ciudadanos. Me refiero, y ustedes se lo imaginan, al vergonzoso caso de "las y los juanitos" [...] a los diez diputados, ocho mujeres, dos hombres, que entre el primero, el 2 y el 3 de septiembre presentaron sus renuncias $\sin$ dar ninguna razón. Simplemente dijeron: renunciamos. (S.A.)

En el mismo fragmento de su intervención, el analista explica en qué consistió "el pecado": la degradación y el menosprecio a los ciudadanos, así como fraguar un "truco", "una trampa mañosa" y una "burla" al electorado que votó por las candidatas y los candidatos postulados por el partido para hacer campaña:

Lo cual es un truco ya bastante común al que recurren algunos partidos, más que otros, para poner de suplentes algunas gentes que quieren hacer que lleguen a la tribuna sin exponerlos probablemente al escrutinio público.

Es una trampa, es una trampa mañosa, es una burla a los electores, y en este caso simplemente menciono porque resalta al Verde Ecologista, que de 10 tiene a seis "juanitas", cuatro mujeres, dos hombres. (S.A.).

En esta narrativa se muestran aspectos de regulación socio-política y ética, las cuales refieren a que cuatro de las legisladoras renunciantes diputadas provienen de un partido que se representa con una bandera de color verde y que trastoca uno de sus principios, la equidad de género, y que además ha realizado esta acción (postular a unas personas como candidatas y, al obtener el cargo, hacerlas renunciar para que otras se queden) en varias ocasiones:

Pero hay dos agravantes. La primera, que es un partido con una bandera verde, por tanto que los verdes en el mundo incluyen la equidad de género en sus plataformas, es uno de los puntos centrales de cualquier Verde.

Segundo, que no es la primera vez que hacen esto. En el 2006 obligaron a renunciar a ocho legisladoras, seis diputadas, dos senadores. (S.A).

\section{Segunda. La aventurera}

En el imaginario social persiste la idea de la mujer relacionada con el pecado el cual, en el caso de las mujeres, suele estar asociado con la prostitución. Hay canciones populares que nutren este imaginario; por ejemplo, en el cancionero nacional existe una famosa composición, de la década de 1930, de Agustín Lara (1897-1970) titulada "Aventurera", cuya letra comienza, con un tono de reclamo y en modo imperativo diciendo: "Vende caro tu amor" y, enseguida, concibe esta práctica como pecado que, sin embargo, es pagado con piedras preciosas. Así lo menciona en la primera estrofa de su composición: "Vende caro tu amor, aventurera/Dale el precio del dolor, a tu pasado/Aquel, que de tu boca miel quiere/Que pague con brillantes tu pecado".

En la segunda estrofa de la canción, el compositor mexicano menciona la palabra "infamia", cuya emoción de trasfondo es el enojo de un reclamante varón amoroso desencantado: "Ya que la infamia de tu ruin destino/Marchito tu admirable primavera/Haz menos escabroso tu camino/Vende caro tu amor, aventurera".

Así, llama la atención la mención de esa palabra en la narrativa evocada por otro de los analistas del programa durante su intervención, para entender y explicar el proceder de estas mujeres, las coloca en el lugar de la prostitución (es decir, venderse por dinero), aunque casi inmediatamente después de lo dicho trata de matizar este recurso al Ilamarlas "mercenarias" y "de relleno". Sin embargo, el primer atributo, igual alude a una paga, y el segundo, a entrar a un espacio que sobra:

No creo que se den mucha cuenta y tampoco creo que les importe demasiado, si no, no se prestarían a una maniobra infame, que si lo pusiéramos en términos monetarios $y$ dijéramos cuando una mujer vende su cara, cuerpo por dinero, y lo hace para una cosa, digamos, como éstas, seguramente le resultaría insultativo* el calificativo; pero, las podríamos llamar "mercenarias", las podrías llamar, no sé, "de relleno". (L.C.) (Las cursivas son de la autora).

Pero no sólo trata de suavizar o matizar su dicho al concebirlas primero, en el imaginario de Agustín Lara, de aventureras, esto es, que se venden a cambio de dinero, sino posteriormente las exime de haberles posicionado en la ignorancia y la despreocupación al atribuirle esta "maniobra infame" a "los verdes" (esto es, a los del Partido Verde Ecologista de México), calificándolos de

\footnotetext{
* En este fragmento de la narrativa del autor, llama la atención el uso de la palabra "insultativo", que no se encuentra registrada en el diccionario de la Real Academia Española. Ramírez \& Estrada (2003: 335), explican que, en el caso de Argentina, "mientras el insultivo actúa como estrategia de cortesía -intensificando la cortesía positiva o mitigando la afrenta a la cortesía negativa-, el insultativo se constituye en una intensificación de la amenaza de las imágenes positiva (en caso de reproche) y negativa (en el caso de la amenaza) del oyente". Y sintetizan: "Parafraseando a los propios hablantes el insultivo es una marca de familiaridad amistosa en tanto el insultativo es lisa y llanamente una agresión".
} 
"impostores" y que, al igual que otros partidos políticos, "tienen cola que les pisen":

Yo estoy seguro que no se dan cuenta, no soy en absoluto optimista, Sergio, sobre lo que "los verdes" pueden hacer o su capacidad de rectificar, no tengo la impresión de qué es, no les preocupe, en fin, vaya a variar su comportamiento [...) Lo que me asombra es un sector muy amplio de la opinión pública que sigue creyendo en eso. Es decir, ellos siguen en su línea, fueron unos impostores la legislatura anterior, y ahora han prometido un montón de cosas, que tampoco van a cumplir, empezando por ésta [...] Y digo el Verde, y digo el PRI, y digo el PT, y digo el PRD, que todos tienen cola que les pisen en este caso. (L.C.).

Al expresar su desconfianza de que dicho partido (el Verde) cambie esta práctica disfrazada o encubierta bajo el discurso de "la igualdad de las mujeres", el analista sugiere un fatalismo en cuyo trasfondo emocional bien pueden estar el enojo y la frustración.

\section{Tercera. "El dominio masculino"}

En muchos estudios feministas y de género suele estar incluida una de las obras de Pierre Bourdieu (La dominación masculina, 2000), en la cual plantea, muy sintéticamente, la idea de que el sometimiento de las mujeres por los hombres, ellas lo asumen. Así, parafraseando el título de la obra del sociólogo francés, el analista que dio inicio el capítulo del programa de ese día plantea, dudando que las legisladoras renunciantes ignoren "el daño profundo" que causan a la "equidad de género", su participación tanto en la simulación de dicha equidad como en preservar una estructura del poder: el "dominio masculino".

...es inevitable preguntarse si estas legisladoras se dan cuenta del daño profundo que hacen a la equidad de género, porque en el último de los casos se están prestando a la simulación y a la preservación del dominio masculino en los cargos de elección popular. (S. A.).

\section{Cuarta. "Detrás de una mujer, hay un suplente"}

Relacionado con el cuestionamiento anterior, otro de los analistas evocará a aquella frase que dicta que "detrás de un gran hombre, hay una gran mujer", pero invertida para señalar, en este cambio de papeles, que responde a determinados intereses de uno de los llamados poderes fácticos:

...detrás de esas mujeres lo que viene son funcionarios de las televisoras. Son gente que ha trabajado en las televisoras, con lo cual se refuerza la llamada "telebancada", que viene liderada por los diputados del partido Verde. (J. A. C.).

La única mujer analista del programa coincidió en que, en efecto, se trata de colocar a otro que responde a determinados intereses y/o que "tiene cola que le pisen": ...no es nada más la idea de la simulación, sino que es mandar a un candidato porque quieres a otro, y el otro tiene cola que le pisen [...] ya sea porque pertenece a una corporación, en este caso haya trabajado en una televisora, o porque no tiene una reputación limpia, o incluso porque los electores de esa localidad o los de ese partido, en caso que sea una lista plurinominal no lo hubiesen aceptado. (M.A.C.).

La analista advierte que se trata de una cuestión "de género" en dos sentidos: 1) seleccionar a una mujer, pero como "parapeto" y 2) cumplir con la obligación de los partidos de postular un porcentaje determinado de mujeres. Así lo expone:

Es de género en el sentido que a lo mejor a esa mujer que escogieron de parapeto tiene más chance de ser elegida, y es de género en el sentido de que todos los partidos tienen la obligación de poner 30 por ciento, creo es, de mujeres en las candidaturas. Pero en realidad lo que quieren es engañarnos, no decirnos quién está atrás, porque esa persona no tendrá ninguna posibilidad de ser electo. (M.A.C.) 
Para la analista este caso está relacionado con el caso "Juanito" que, para ella, representa "uno de los atracos más evidentes"; de ahí que se le haya denominado a este caso "las juanitas". Otro de los analistas interviene para aclarar la diferencia entre ambos casos, aunque ella mantiene su postura:

Con una diferencia, perdón, rápidamente. Les llamaron "juanitas" a estas diputadas que renunciaron, pero en realidad con Juanito sí se dijo cuál sería la jugada. Lo que pasa es que ahí Juanito a la mera hora fue que dijo: "no, pues de aquí ya no me muevo". (J.A.C.).

\section{Cinco. "El contubernio"}

Casi en la última parte de este bloque del programa se tematizó sobre la reglamentación electoral, pero ya no refiriéndose directamente al caso "las juanitas" sino directamente a los partidos políticos a los cuales señalan de complicidad:

...Si los partidos son capaces de hacer esta burla, es porque los otros partidos se lo toleran [...] la reacción que hubo inmediatamente después; por supuesto que el grupo parlamentario del PAN, las mujeres, sobre todo, sacaron un comunicado condenando la simulación, y lo mismo hizo el PRD y Manlio Fabio Beltrones, y todos se llenaron la boca de ética, pero dejaron pasar un día más y empezaron a decir: "pero la ley lo permite". (S. A). ...ahora podríamos decir, se podrían vigilar entre ellos, y lo que vemos más bien es un contubernio entre los partidos, en donde el uno se tapa al otro. (M.A.C.).

...cuando se va rebajando los estándares de procedimientos de los propios partidos y dicen: "a ver, nosotros hemos denunciado al de enfrente porque hace esto; nosotros lo vamos a hacer pero no es tan grave en nuestro caso". (L. C.).

Así, observaron que los partidos carecen de ética y la ciudadanía de "un mecanismo para premiar o castigar a los legisladores".

...una agenda que tendría que estar levantando el Congreso, los legisladores, es represtigiarse frente a la ciudadanía, porque realmente están por los suelos precisamente porque carecen de toda ética pública. (M.A.C.).

...mientras no tengamos ese mecanismo, evidentemente los legisladores hacen lo que les viene en gana. Lo han hecho una y otra vez porque no van a rendir cuentas. Saben que los electores no tienen manera de sancionar (J.A.C).

\section{"Hoy por Hoy"}

\section{Primera. "Las amantes"}

Al inicio de la entrevista, en la pregunta formulada por el entrevistador a la entrevistada, emergió el prejuicio sexista que refiere a hombres que usan mujeres con quienes, de acuerdo con el imaginario, mantienen una cercanía de carácter sexual, intra y extra marital, para obtener ciertos fines. En la evocación de este prejuicio llama la atención, incluso, la ausencia del sujeto que realiza la acción ("la farsa"):

Esta farsa, en donde, bueno, hay ciertas candidaturas que tienen que ir para mujeres $y$, pus, ponen a sus secretarias, a sus amigas, a sus esposas o a sus amantes, para que llegando al Congreso renuncien. (C. P.).

El cuestionamiento del entrevistador estaba dirigido, en apariencia, a los hombres, sin embargo, dado el ocultamiento del sujeto de la acción y que son mujeres las involucradas, en un contexto de coexistencia de una cultura machista, la crítica denigraba más a las mujeres que a los hombres. Es probable que detrás de la expresión "esta farsa" y este prejuicio sexista se encuentra, más que un enojo, cierta ira.

\section{Segunda. "La prestanombres y el truhan"}

La entrevistada en el programa radiofónico no siguió el prejuicio expuesto por el entrevistador, sino decidió nombrar a las legisladoras renunciantes como "prestanombres" y arremeter contra los suplentes: 
...los truhanes que están entrando en lugar de las mujeres, en lugares destinados por ley para las mujeres, lo podrán finalmente hacer efectivo hasta el próximo periodo legislativo. No pudieron encontrar en la ley algo que permitiera que juraran en este momento. (E. U.).

Asimismo, introdujo el incumplimiento de las "cuotas de género" y la violación de los tratados internacionales firmados por el gobierno de México, como la Convención sobre la Eliminación de toda forma de Discriminación contra la Mujer (CEDAW, por sus siglas en inglés), así como la propia Constitución:

...que se reconozca que se violaron tres tratados internacionales [...] en el caso de América, la convención de Quito [...] particularmente CEDAW, establecen que las cuotas de género son de juro y de facto, es decir, no se trata solamente del numerito formal de que haya determinado número, sino de que la Cámara garantice el que son mujeres que se van a quedar a legislar. Estamos claramente incumpliendo, incumpliéndole a la democracia, incumpliéndoles a las mujeres en el país, engañándolas electoralmente, pero incumpliendo tratados internacionales.

...me parece que para ellos será un ritual, un mero trámite de jurar que harán cumplir la Constitución, entrando haciéndole trampa a la Constitución. (E. U.)

\section{Tercera. "Usos y costumbres"}

Al concebir como un cinismo esta práctica (de postular y quitar, luego de que ganan, a candidatas y candidatos) en el partido político que se ha dicho lo ha hecho en varias ocasiones, el PVEM, la entrevistada incorporó la noción de "usos y costumbres", la cual se refiere a las prácticas sociales y culturales ancestrales, entre las comunidades o los pueblos indígenas del país:

Lo del partido Verde ya es de un cinismo total; ellos ya tienen incluso hasta un machote, un formato con el que hacen estos cambios; se ha vuelto para ellos un uso y costumbre [...] que además lleva detrás, y por ello la urgencia, la presencia y ya la entrada de funcionarios de Televisa y de Azteca. (E. U.)

En la actitud señalada en esta narrativa, "el cinismo, connota impotencia $y$, por tanto, en el trasfondo emocional, coraje y enojo.

\section{Artículo periodístico}

\section{Primera. "La época dorada del PRI"}

Para hacer referencia a la retórica de antaño de los políticos del Partido Revolucionario Institucional (PRI), refiriéndose concretamente al senador priista Manlio Fabio Beltrones, el articulista recurrió, en tono irónico, una narrativa del imaginario que evoca un periodo de gran esplendor, en este caso de un instituto político que durante siete décadas continuas detentó el poder como "partido único", inclusive, validaba que algunos de sus gobernantes argumentaran que había acciones que "no beneficiaban ni perjudicaban, sino todo lo contrario": se trata de "la época dorada":

Interrogado sobre el tema [Las juanitas], el senador Beltrones, siempre eficaz en el manejo de la retórica florida que prevaleció en la época dorada del PRI, declaró no estar convencido de que las renuncias constituyen violaciones a la ley, pero después, con esa lógica maniquea de los políticos, reconoció que sí son actos que no dignifican al Congreso [...[ recordó al inefable Luis Echeverría y concluyó erróneamente que las renuncias de las juanitas no le hacían daño a nadie (ni nos benefician ni nos perjudican, sino todo lo contrario). (J. C.)

Una afrenta a la dignidad, percibida por el analista de parte de los políticos de este partido, es la emoción que hace detonar esta narrativa.

\section{Segunda. "Por unas cuantas monedas"}

En otra parte de su artículo evoca el título de una canción norteña que refiere a la mujer que, al igual que el imaginario de la aventurera que se prostituye, traiciona y cambia el amor de un hombre por dinero, la 
cual es cantada por varios intérpretes y cuya primera estrofa a letra dice: "Por unas cuentas monedas cambiaste tu vida/ por unas cuantas monedas cambiaste mi amor/ por la ambición al dinero te encuentras perdida/ y yo creyéndome tuyo hoy sufro por tu canción". El articulista escribe lo siguiente:

"Las juanitas" se convirtieron en el mil usos que por unas cuentas monedas te guarda lugar en la cola. Al contrario de Juanito, quien prometió públicamente renunciar en favor de Clara Brugada en caso de salir victorioso. (J.C.)

Detrás de las traiciones suele haber dolor, las cuales provocan emociones como la tristeza, incluso, la nostalgia.

\section{Tercera. "Las juanitas de San Lázaro"}

Siguiendo el estilo de la picaresca y evocando tanto al título como al personaje de una de las obras fundadoras y más importantes de este género (conocida como Lazarillo de Tormes, de autor anónimo), el articulista construye su crítica refiriéndose a las "pícaras" legisladoras:

Ocho diputadas marrulleras escogidas por sus partidos políticos con el único propósito de aparentar que cumplían con las cuotas de género...

Con esta burda maniobra, ellas, sus suplentes y sus respectivos partidos políticos pretendían burlarse olímpicamente de las cuotas de género...

En un sistema electoral, que pretende ser democrático, las cuotas de género, diseñadas históricamente para garantizar el acceso equitativo de la mujer a los puestos de elección popular, no deberían ser materia de burla ni de estrategias políticas.

...las pícaras juanitas de San Lázaro prometieron lo mismo, pero en lo oscurito. Engañaron al sistema electoral asumiendo a priori, y a espaldas de los votantes, el compromiso de renunciar en favor de suplentes que rondaban cínicamente afuera del salón de plenos esperando tomar posesión; eran amigos, esposos y familiares de las propias juanitas. (J.C.).

Es importante mencionar que la picaresca es un género literario que narra las peripecias de su personaje principal, el pícaro, cuyas características son: la marrullería, la burla y el engaño, para conseguir sus fines, sin buscar o pretender el ascenso social.

\section{Cuarta. "El fraude"}

Prácticamente en cada proceso electoral en México, emerge el imaginario del fraude. El autor del artículo refiere a esta práctica en dos momentos: 1) cuando, dirigiéndose al senador del PRI (Beltrones), le cuestiona, mediante dos preguntas, sus declaraciones para justificar la renuncia de las diputadas; y 2) cuando una legisladora del mismo partido, una de "las juanitas", declaró que las plurinominales, al ser posiciones de los partidos políticos, éstos pueden hacer lo que les conviene. Así se dirigió al priista sobre el fraude:

...¿qué pensaría el senador de un pintor famoso que, tras recibir un jugoso anticipo para pintar el retrato del ilustre tribuno, realizara la obra a través de su primo, un pintor ramplón de brocha gorda? ¿Concluiría que el acto es un fraude, como lo es, o con el mismo desparpajo lo calificaría como un acto que no dignifica al arte pictórico? (J.C.).

El término "desparpajo" hace referencia a la facilidad que se tiene para actuar en una determinada situación o ambiente, actuación que es atribuida, también al pícaro. El uso de este término sugiere que quien recurre a ella plantea que, prácticamente, no hay manera de oponerse a quien así se conduce. Por tanto, hay cierta frustración y, también, disgusto y enojo.

\section{Conclusiones}

En esta construcción mediática de un caso de violencia política de género contra las mujeres se pudo observar, mediante un enfoque de las emociones, una gran irritación de analistas de medios de comunicación, la cual provocó, en un entramado emocional, la detonación de distintas narrativas y prejuicios sexistas, propios de 
imaginarios y la cultura machista $y$, de manera simultánea, un enjuiciamiento mediático y, por tanto, público a los partidos políticos, por el trastocamiento de valores y normas socio-políticas establecidas legalmente para el juego político, como son las llamadas "cuotas de género".

Se mencionó, por supuesto, a las diputadas renunciantes a quienes, pese a que en algunos momentos se les otorgó el beneficio de la duda, su acción detonó una serie de narrativas y prejuicios sexistas, así como otros aspectos de interés para la reflexión y el análisis crítico:

- El uso de mujeres para introducir en el Congreso varones que responden a intereses de determinados grupos empresariales.

- El uso de mujeres para introducir al Congreso varones rechazados por su comunidad o de dudosa reputación.

- El desconocimiento o el desinterés de algunas mujeres sobre el propósito de las cuotas de género.

- La contribución, inconsciente, de las mujeres para preservar el dominio masculino.

- La degradación de la ética de los partidos y de la clase política.

- La torcedura y violación de la ley electoral, de la propia Constitución y de los tratados internacionales.

- La instauración de un modelo o una práctica para simular, a la manera de usos y costumbres, el cumplimiento de las cuotas de género.

- Acomodar o interpretar a modo, preceptos de la ley electoral, la Constitución y tratados internacionales.

- Las plurinominales como una figura propensa para armar o cometer simulaciones, engaños o fraudes electorales.

Se pudo conocer que el efecto más trascendente que tuvo la renuncia de las nueve diputadas federales fue en beneficio a las mujeres, pues el
TEPJF estableció que las fórmulas de las candidaturas se formaran con personas del mismo género; sin embargo, este acontecimiento detonó una serie de narrativas y prejuicios sexistas, como los aquí expuestas, que refuerzan, directa y/o indirectamente, la violencia de género contra las mujeres y que, de alguna manera, podrían impactar las iniciativas para seguir avanzando en el anhelado tránsito de nuestro país hacia un auténtico régimen democrático.

\section{References}

Alexander, Jeffrey Charles (1992) Las teorías sociológicas desde la Segunda Guerra Mundial. Barcelona: Gedisa.

Ariza, Marina (2016) Emociones, afectos y sociología. Diálogos desde la investigación social y la interdisciplina. México: Universidad Nacional Autónoma de México/Instituto de Investigaciones Sociales.

Barquet, Mercedes (2012) De la inutilidad de la cuota de género. La diputada que no quería ser. Nota introductoria Sergio Dávila Calderón. México: Serie Comentarios a las Sentencias del Tribunal Electoral/Tribunal Electoral del Poder Judicial de la Federación.

Bourdieu, Pierre (2000) La dominación masculina. Barcelona: Anagrama.

Cornelius, Randolph (1996) The Science of Emotion . Research and Tradition in the Psychology of Emotion. Englewood Cliffs (New Jersey): Prentice-Hall, Inc.

Durkheim, Emile (2008) Las formas elementales de la vida religiosa. Madrid: Alianza Editorial.

Fericgla, Josep Maria (2000). "Cultura y emociones. Manifiesto por una Antropología de las emociones. Conferencia inaugural del III Seminario sobre Estados Modificados de la Consciencia y Cultura" en Fundación Josep M. Fericgla [En línea]. Manizales (Colombia): Universidad de Caldas. Disponible en línea en: http://josepmfericgla.org/2011/ cultura y-emociones [16 de enero de 2018]

Gaytán, Patricia (2010) La contribución del estudio del cuerpo y las emociones a las teorías sociológicas de la acción (vs. los estudios culturales) en Sociológica. Revista del Departamento de Sociología, Vol. 25, núm. 72, pp. 139-164. México: Universidad Autónoma Metropolitana, Unidad Azcapotzalco.

González, Rosa María \& Araiza, Alejandra (2018) "Gobernar desde la izquierda: el caso de una ex jefa delegacional del Distrito Federal (hoy Ciudad de México)" en Rosa María Valles (Coordinadora). Ciudadanía en ejercicio: Sendero escarpado. Presidentas municipales en México, pp. 165-189. México: Plaza y Valdés, 
Gundermann, Hans (2008) "El método de los estudios de caso" en María Luis Tarrés (Coord.) Observar, escuchar y comprender. Sobre la tradición cualitativa en la investigación social, pp. 251-288. México: El Colegio de México.

Inmujeres (2015) "Desigualdad en cifras" en Boletín [En línea] Vol. 1, núm. 8. México: Instituto Nacional de las Mujeres. Disponible en línea en

http://cedoc.inmujeres.gob.mx/documentos_download/BoletinN8.pdf

[23 febrero de 2018]

Jaiven, Ana Lau \& Rodríguez, Roxana (2017) "El sufragio femenino y la Constitución de 1917. Una revisión" en Política y Cultura, núm. 48 pp. 57-81. México: Universidad Autónoma Metropolitana, Unidad Xochimilco.

Krook, Mona Lena \& Restrepo, Juliana (2016) "Violencia contra las mujeres en política" en Política y gobierno, Vol. XXIII, núm. 2, pp. 459-490. México: Centro de Investigación y Docencia Económicas.

Los Editores (2017) "Más mujeres gobiernan" en Revista Alcaldes de México [En línea] No. 84. Marzo. México. Disponible en https://www.alcaldesdemexico.com/expediente-abierto/mas-mujeresgobiernan/ [17 de enero de 2018]

Micheli, Raphaël (2011) "Las emociones como objetos de construcciones argumentativas" en Versión. Estudios de Comunicación y Política núm. 26, pp. 141-166. México: Universidad Autónoma Metropolitana, Unidad Xochimilco.

Ramírez, Silvia \& Estrada, Andrea (2003) "Vocativos Insultivos vs. Vocativos Insultativos. Acerca del caso boludo" en Anuario de Estudios Filológicos, Vol. XXVI, pp. 335-353. Cáceres: Universidad de Extremadura.

Ritzer, George (2012) Teoría sociológica clásica. México: McGrawHill.

Rubin, Gayle (1986) "El tráfico de mujeres: notas sobre la 'economía política' del sexo" en Nueva Antropología, Vol. VIII, núm. 30, pp. 95 145. Distrito Federal: Asociación Nueva Antropología, A.C.

Scribano, Adrián (2016) Sociología de las emociones en Carlos Marx. Buenos Aires: Editorial a Contracorriente.

Sutton, Liz Hamui (2011) "Las narrativas del padecer: una ventana a la realidad social” en Cuicuilco, núm. 52, pp. 51-70. México: Instituto Nacional de Antropología e Historia.

Talamás, Marcela \& Lascurain, Sofía (2016) Protocolo para Atender la Violencia Política Contra las Mujeres. México: Tribunal Electoral del Poder Judicial de la Federación.

Virgen, Lucy (2013) "17 de octubre de 1953 - Derecho al voto para la mujer en México" en Red Universitaria de Jalisco [En línea]. México: Universidad de Guadalajara. Disponible en: http://www.udg.mx/es/efemerides/17-octubre-0 [21 de diciembre de 2017]

Zavaleta, Ruth (2014) “Cuotas de género, una medida necesaria” en Letras Libres [En línea] núm. 184. Disponible en: http://www.letraslibres.com/mexico/cuotas-genero-una-medidanecesaria 